\title{
Effects of CS amount on conditioned taste aversion at different CS-US intervals
}

\author{
ROBERT DEUTSCH \\ York University, Downsview, Ontario, Canada M3J 2R7
}

\begin{abstract}
Previous studies on the effect of CS amount/duration on the conditioning of taste aversion have reported that animals having greater contact with the CS acquire greater aversion. These findings appear to contradict studies of CS preexposure, which show that greater contact with the CS results in less aversion. In the present research, the effect of CS amount was shown to depend on the CS-US interval. Thus, a $10-\mathrm{ml}$ CS $10.15 \%$ saccharin) at 3-and 9-h CS-US intervals produced less aversion than a 1-ml CS, but there was no significant effect of CS amount at a 30-min interval. These results suggest a twoprocess interpretation of the delay gradient in conditioned taste aversion: one process (learned safety) is dominant at relatively long CS-US intervals, and a different process becomes dominant at short intervals.
\end{abstract}

It is now well established that conditioned taste aversion, although it can be obtained with CS-US intervals considerably longer than those used in other conditioning paradigms, nevertheless shows an orderly delay-of-reinforcement gradient (e.g., Garcia, Ervin, \& Koelling, 1966; Nachman; 1970). The traditional explanation for delay-of-reinforcement phenomena, i.e., that the weaker conditioning at longer CS-US intervals is due to the gradual decay of the CS trace, has difficulty accounting for some of the characteristics of the delay-ofreinforcement gradient in conditioned taste aversion. The major problem concerns experiments which show that presenting a CS twice in succession, thereby (presumably) strengthening the trace, can result in less conditioning than presenting it just once (Best \& Barker, 1977; Bond \& DiGiusto, 1975; Domjan \& Bowman, 1974; Kalat \& Rozin, 1973). Because of evidence such as this, recent discussions of the delay gradient in conditioned taste aversion have centered around concepts such as "learned safety" (Kalat \& Rozin, 1973), "learned noncorrelation" (Kalat, 1977), or "learned familiarity" (Best \& Barker, 1977). According to these theories, the reason for the delay gradient is that, at longer intervals, the animal is more likely to learn that the $\mathrm{CS}$ is safe (or noncorrelated, or familiar), and hence acquires less aversion. Two presentations of the CS allow for greater learning of safety and therefore

This research was supported by a grant from the Atkinson College Minor Research Fund. I wish to thank C. Methot for assistance in collecting data and Michael Domjan, University of Texas at Austin, for some valuable discussions. Requests for reprints should be sent to Robert Deutsch, Department of Psychology, York University, Atkinson College, 4700 Keele Street, Downsview, Ontario, Canada M3J 2R7. less aversion. Similarly, learned safety theory is compatible with the finding that familiarization with a taste both increases preference for the taste (i.e., attenuates neophobia) and impairs the conditioning of aversion to that taste (Nachman \& Jones, 1974; Siegel, 1974). Further support for learned safety theory is provided by studies which show that the attenuation of aversion is positively related to the duration as well as the number of preexposure trials (Domjan, 1972; Elkins, 1973; Fenwick, Mikulka, \& Klein, 1975). Thus, the greater the experience with the taste, the more it is classified as safe, or at least as one not followed by significant consequences (aversive or otherwise).

Consideration of the effects of CS amount (or duration, which is normally correlated with amount) presents a paradox for learned safety theory. The paradox centers around the effects of experience with the CS on the acquisition of aversion. As defined by studies which involve repeated CS preexposures or which vary the duration of CS preexposure, "greater experience with the CS" results in less (or at most equal) aversion being acquired. On the other hand, according to studies in which experience with the $\mathrm{CS}$ is manipulated by varying CS amount/duration in the CS-US pairing rather than in preexposure (Barker, 1976; Bond \& DiGiusto, 1975), "greater experience with the CS" apparently results in greater (or at least equal) acquisition of aversion.

The present research offers an empirical resolution of this paradox: it shows that at relatively long CS-US intervals (approaching those used in CS preexposure studies) greater CS amount/duration does result in less acquisition of aversion but that this relationship does not hold at a relatively short CS-US interval (one typically used in CS duration studies). 


\section{METHOD}

Forty experimentally naive Wistar rats weighing 250-340 g were individually housed and remained in their home cages throughout the experiment. Purina Rat Chow was continuously available and, for 5 days, water was available on a $30 \mathrm{~min} /$ day schedule. On Day 6, the conditioning day, each rat was assigned to one of eight groups ( $n=5$ for each group). Six of the groups were experimental groups. The subjects in these groups received either 10 or $1 \mathrm{ml}$ of $0.15 \%$ sodium saccharin $(w / v)$ to drink, and $9 \mathrm{~h}, 3 \mathrm{~h}$, or $30 \mathrm{~min}$ after the onset of drinking, they were given a $10-\mathrm{ml} / \mathrm{kg}$ intraperitoneal injection of $0.15 \mathrm{M} \mathrm{LiCl}$. Subjects in the two control groups received either 10 or $1 \mathrm{ml}$ of saccharin and were injected with $10 \mathrm{ml} / \mathrm{kg}$ of $0.15 \mathrm{M} \mathrm{NaCl} 30 \mathrm{~min}$ later. Consumption durations were recorded (four of the subjects took slightly longer than 30 min to consume the $10-\mathrm{ml}$ of CS solution, but none of these subjects was in the 30-min CS-US interval group). On Day 7, all subjects were given access to water for $30 \mathrm{~min}$. This was followed, on Day 8, by a 30 -min single-bottle test, with $0.15 \%$ saccharin as the test solution.

\section{RESULTS}

On the conditioning day, as expected, subjects in the $10-\mathrm{ml}$ groups took much longer to consume the saccharin than subjects in the 1-ml groups (mean for $10-\mathrm{ml}$ groups $=23.3 \mathrm{~min}$, mean for $1-\mathrm{ml}$ groups $=1.0 \mathrm{~min}$ ), but there were no significant differences in consumption duration at different CS-US intervals for a given CS amount.

Figure 1 plots the mean saccharin intakes on the test day for all groups. Overall ( 2 by 4 ) analysis of variance revealed a significant effect of CS amount $[F(1,32)=33.1, p<.01]$, a significant effect of injection treatment ( $\mathrm{LiCl}$ at three CS-US intervals or control) $[\mathrm{F}(3,32)=43.1, \mathrm{p}<.01]$, and a significant interaction $[F(3,32)=5.45, p<.01]$. Further analysis using the Newman-Keuls test showed that each experimental group consumed less saccharin than the corresponding control group (all ps $<.01$ ), except for Group $9 \mathrm{~h}-10 \mathrm{ml}(\mathrm{p}>.05)$. Comparison of the control groups shows that the $10-\mathrm{ml}$ group consumed significantly more than the $1-\mathrm{ml}$ group $(p<.05)$.

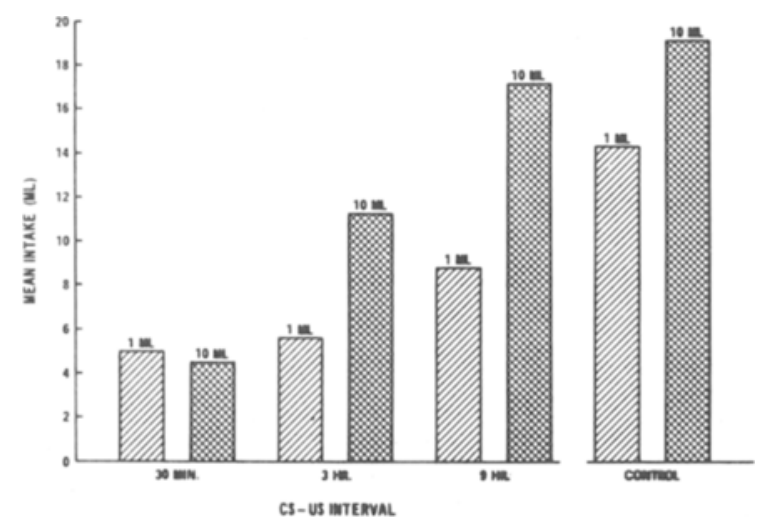

Figure 1. Mean intake of $0.15 \%$ saccharin during the postconditioning test.
In order to assess specifically the effect of the magnitude of CS-US interval in combination with CS amount, analysis of variance ( 2 by 3 ) was performed for the experimental groups only. This analysis revealed a significant effect of the CS-US interval $[\mathrm{F}(2,24)=24.45, \mathrm{p}<.01]$, CS amount $[F(1,24)=21.64, \quad p<.01]$, and an interaction $[F(2,24)=7.36, p<.01]$. Examination of the intake levels in the different groups in Figure 1 shows that the interaction is attributable to the fact that at the 9-h and 3-h intervals the $10-\mathrm{ml}$ groups consumed more saccharin than the 1-ml groups (ps $<.05$, Newman-Keuls), whereas there was no difference between the CS-amount groups at $30 \mathrm{~min}$ (p > .05).

\section{DISCUSSION}

Other investigators have reported that conditioning of taste aversion increases with amount/duration of the CS (Barker, 1976; Bond \& DiGiusto, 1975). The present research found no reliable effect of CS amount/duration at a short CS-US interval (30 $\mathrm{min})$ and less aversion with greater CS amount/ duration at longer CS-US intervals. The failure to find greater aversion with greater CS contact at the 30-min interval is not entirely unexpected, in that in some other experiments the phenomenon did not emerge or was found to be highly parameterdependent (cf. Barker, 1976; Domjan \& Levy, 1977; Smith \& Morris, 1963). Presumably, a different choice of CS and US intensity parameters (cf. Bond \& DiGiusto, 1975) and/or the use of a twobottle testing procedure (cf. Barker, 1976) would reveal increased aversion with increased CS amount at short CS-US intervals.

The most striking aspect of these results is that, at longer CS-US intervals, greater CS amount/ duration produces less conditioning of aversion. These results are difficult to account for in terms of trace decay (a longer CS should result in better CS-US contiguity), and also appear to be inconsistent with the view (Testa \& Ternes, 1977) that interoceptive consequences of ingestion play a vital role in bridging the CS-US interval (more solution ingested should result in more pronounced interoceptive consequences). The results at longer intervals are, however, in essential accord with learned safety/noncorrelation/familiarity theory (Best \& Barker, 1977; Kalat, 1977; Kalat \& Rozin, 1973). Presumably the longer CS has a greater chance of being associated with the ensuing period of "safety" [or with "safe" contextual cues (Wagner, 1976)], and the learned safety interferes with or counteracts the taste-toxicosis association. Data from the control groups, showing corresponding differences in the neophobic response to saccharin, lend further support to the learned safety view (cf. Siegel, 1974). 
Although learned safety provides a plausible account of the CS amount/duration effect at long intervals, it has difficulty accounting for the present failure to find the same effect at a short interval, and for reports that greater CS amount/duration can produce greater aversion (Barker, 1976; Bond \& DiGiusto, 1975). One possible explanation is that a short interval does not allow for the buildup of sufficient learned safety to interfere with the acquisition of aversion, thus the magnitude of conditioned aversion depends on a different process (i.e., trace decay). This entire pattern of results suggests that the delay gradient in conditioned taste aversion involves at least two processes: one process, dominant at relatively long intervals (and especially when the CS is long), may be characterized as learned safety/noncorrelation/familiarity, whereas the other process (trace decay) becomes dominant at relatively short CS-US intervals. The question of "how short is short" probably depends on variables such as US intensity. The present research may be seen as providing one example of the interaction between these two processes (cf. Best \& Barker, 1977; Best \& Gemberling, 1977; Kalat, 1977).

\section{REFERENCES}

BARKER, L. M. SC duration, amount, and concentration effects in conditioning taste aversion. Learning and Motivation, 1976, 7, 265-273.

BEST, M. R., \& BARKER, L. M. The nature of "learned safety" and its role in delay of reinforcement gradient. In L. M. Barker, M. R. Best, \& M. Domjan (Eds.), Learning mechanisms in food selection. Waco, Tex: Baylor University Press, 1977.

Best, M. R., \& Gemberling, G. A. Role of short-term processes in the conditioned stimulus preexposure effect and the delay of reinforcement gradient in long-delay taste aversion learning. Journal of Experimental Psychology: Animal Behavior Processes, 1977, 3, 253-263.

Bond, N. W., \& DiGiusto, E. L. Amount of solution drunk is a factor in the establishment of taste aversion. Animal Learning \& Behavior, 1975, 3, 81-84.
Domjan, M. CS preexposure in taste-aversion learning: Effects of deprivation and preexposure duration. Learning and Motivation, 1972, 3, 389-402.

Domjan. M., \& Bowman. T. G. Learned safety and the CS-US delay gradient in taste-aversion learning. Learning and Motivation, 1974, 5, 409.423.

Domjan. M., \& Levy, C. J. Taste aversions conditioned by the aversiveness of insulin and Formalin: Role of CS specificity. Jourmal of Experimental Psychology: Animal Behavior Processes, 1977, 3. 119-131.

Elkins, R. L. Attenuation of drug-induced bait-shyness to a palatable solution as an increasing function of its availability prior to conditioning. Behavioral Biology, 1973, 9. 221-226.

Fenwick, S., Mikulka, P. J., \& Klein, S. B. The effect of different levels of pre-exposure to sucrose on the acquisition and extinction of a conditioned aversion. Behavioral Biology, 1975, 14, 231.235.

Garcia, J., Ervin, F. R., \& Koelling, R. A. Learning with prolonged delay of reinforcement. Psychonomic Science, 1966, 5 , $121-122$.

KaLAT, J. W. Status of "learned safety" or "learned noncorrelation" as a mechanism in taste aversion learning. In L. M. Barker, M. R. Best, \& M. Domjan (Eds.), Learning mechanisms in food selection. Waco, Tex: Baylor University Press, 1977.

KALAT, J. W., \& Rozin, P. "Learned safety" as a mechanism in long-delay taste-aversion learning in rats. Journal of Comparative and Physiological Psychology, 1973, 83, 198-207.

NACHMAN, M. Learned taste and temperature aversions due to lithium chloride sickness after temporal delays. Journal of Comparative and Physiological Psychology. 1970, 73, 22-30.

NACHMAN, M., \& JonEs, D. R. Learned taste aversions over long delays in rats: The role of learned safety. Journal of Comparative and Physiological Psychology, 1974, 86, 949-956.

SIEGEL, S. Flavor preexposure and "learned safety." Journal of Comparative and Physiological Psychology, 1974, 87, 1073-1082.

Smith, J. C., \& Morris, D. D. The use of X-rays as the unconditioned stimulus in five-hundred-day-old rats. Journal of Comparative and Physiological Psychology, 1963, 56, 746.747.

Testa, T. J., \& Ternes, J. W. Specificity of conditioning mechanisms in the modification of food preferences. In L. M. Barker, M. R. Best, \& M. Domjan (Eds.), Learning mechanisms in food selection. Waco, Tex: Baylor University Press, 1977.

WAGNER, A. R. Priming in STM: An information-processing mechanism for self-generated or retrieval-generated depression in performance. In T. J. Tighe \& R. N. Leaton (Eds.), Habituation: Perspectives from child development, animal behavior, and neurophysiology. Hillsdale, N.J: Erlbaum, 1976.

(Received for publication November 22, 1977; revision accepted February 8, 1978.) 